\title{
Interlibrary Loan Requests for Locally Available Materials: WorldCat Local's Impact
}

\section{Megan Gaffney}

\begin{abstract}
Several studies have researched the reasons and patterns for academic library users' interlibrary loan requests for materials already available at their college or university library. This study examines interlibrary loan statistics at the University of Delaware for four academic years to determine whether WorldCat Local impacts requests for locally available material. Data show that WorldCat Local does reduce this type of request, particularly when users are requesting returnable loans of materials such as books or audiovisual items rather than copies of articles.
\end{abstract}

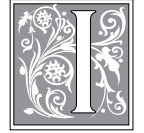

nterlibrary loan (ILL) requests in academic libraries are routinely canceled simply because the requested material is available in the requester's own library. Examining data on ILL requests for locally owned titles is an invaluable way to evaluate how well researchers are finding materials in their own library and how well library interfaces are assisting them in locating what they need. Research tools such as citation linkers, local OPACs, e-journal knowledge bases, and WorldCat exist to alert patrons to locally held materials, yet users routinely ask ILL staff to borrow books and journals from another library when they can be found in the library's own stacks or through an electronic subscription. OCLC's WorldCat Local (WCL) has been introduced as a search tool that can integrate citations, local holdings, worldwide holdings, and delivery functionality into one interface. One way to assess the usability and effec- tiveness of WorldCat Local is to examine ILL requests placed by users for locally available materials when searching WCL, as ILL cancellations for local materials are often viewed as indicators of researchers' ability to navigate resources and services at their own libraries. The purpose of this study is to analyze ILL request cancellation data at the University of Delaware Library before and after implementation of WorldCat Local to evaluate the impact of this new search and delivery interface on request cancellations.

\section{Environment}

The University of Delaware (UD) in Newark, Delaware, is a state-supported research university with more than 16,000 undergraduate students, 3,500 graduate students, and 1,000 professional and continuing education students enrolled in seven colleges. ${ }^{1}$ During the 2009-2010 academic year, the university had more than 1,100 faculty positions. ${ }^{2}$

Megan Gaffney is Coordinator, Interlibrary Loan and Document Delivery Services, at the University of Delaware Library; e-mail: gaffneym@udel.edu. (C) Megan Gaffney 


\section{Interlibrary Loan at the University of Delaware Library}

The University of Delaware Library extends ILL borrowing privileges to all current and retired faculty and staff, graduate students, and undergraduate students. There is no limit to the number of requests eligible users may place, and the library pays all borrowing and shipping fees associated with ILL transactions up to a certain maximum cost. ILL policy states that materials owned by the library will not be requested on ILL unless they are missing, lost, at the bindery, or in preservation. All requests for locally available items are canceled by ILL staff, and the user is provided with the call number and location of the item. Requests for items that are checked out also are canceled, and the user is asked to place a recall request through an online form. ILL staff attempt to borrow any item that is requested and not locally owned; there are currently no procedures in place for establishing whether a request is being made for research purposes or personal use.

The Interlibrary Loan Office in the Morris Library processes all ILL borrowing and lending requests for the university. If UD users place ILL requests for items that are actually held in a branch library or in the Library Annex, those requests are canceled and counted as requests for locally owned materials. ILL staff process all requests using OCLC ILLiad software. Customized ILLiad Web pages are used by all ILL patrons for placing new requests, retrieving electronically delivered articles, renewing checked out items, and tracking the statuses of their requests.

The library has developed its own link resolver, Get It!, to parse OpenURLs and point users from citations in databases to holdings in the online catalog (DELCAT), electronic journal holdings (a separate Web page for searching the library's electronic journal knowledge base), and the ILLiad request forms. When users click the Get It! button in a database or WorldCat Local, a new window opens and green checkmarks appear, as appropriate, to in- dicate local holdings or full-text electronic availability. The last option in this new window is a link to log in to ILLiad Web pages to place a request. When requests are placed through this linking service, ILLiad records the source of the request so ILL staff can track request frequency and patterns from of Get It!-enabled databases. This article's discussion of requests submitted via WorldCat Local is based on the data recorded in ILLiad requests, which show the user clicked the Get It! button and followed its link to the ILL request form.

\section{Interlibrary Loan and WorldCat Local}

WorldCat Local is a search interface developed by OCLC for the WorldCat database and other research tools, and it contains records for over 164 million books, 14.5 million dissertations and theses, 200,000 million articles, and more. ${ }^{3}$ During the years covered by this analysis, the University of Delaware Library implementation of WorldCat Local searched across WorldCat and several article citation databases, including ArticleFirst, ERIC, PubMed, and the British Library serials database. WorldCat Local at UD has since been customized to include an option for searching across several subscription databases, normally accessed via differing platforms, in addition to the standard WCL search. By default, WorldCat Local ranks search results to place locally available materials at the top of the list and retrieves holdings and circulation data from items in the local catalog, DELCAT, through a Z39.50 connection. Holdings information is determined by whether the library's symbol, DLM, is on the WorldCat record for that item, and the DELCAT record must include an OCLC number.

When users click on a record for a locally held item in WorldCat Local, they see the University of Delaware Library call number, location, and availability information. In addition to library-specific information, users can view the WorldCat bibliographic data, a list of other libraries 
that own the material, and, when available, links to electronic content such as tables of contents, previews, or full text through HathiTrust or Google Books, and more. When an item is not held by the library, or it is lost or missing from the library, a "Request Item through Interlibrary Loan" button appears on the record in the local availability area. This button links to the Get It! Service, which opens a new window that checks local holdings and includes an option for placing an ILL request.

The University of Delaware Library implementation of WorldCat Local is customized to reflect local resource sharing policies. If WorldCat Local shows that a nonserial item is available for use at the University of Delaware, the ILL request button does not appear on that record. For WorldCat Local purposes, items that are checked out are considered available because ILL requests are not placed for items in use; users are asked to recall them using a separate library Web form. Serials and the Get It! button are more complicated in the University of Delaware implementation of WorldCat Local. Although call numbers, local catalog holdings, and availability are pulled into the WorldCat Local record view, the Get It! button also appears so that a user can click to check for electronic resources not listed in DELCAT but in the library's electronic journal knowledge base. As a result, it is very easy for a user to place an ILL request for volumes and issues that are actually held by the library, either in print or electronically, because there is nothing working in the background to restrict the ILL button's appearance based on volume-level holdings.

WorldCat Local makes interlibrary loan a much more visible and accessible service, especially when it is promoted as a library's primary search interface. The University of Washington Libraries (UW) analyzed their ILL data after implementing WorldCat Local and found a 92 percent increase in ILL borrowing requests in the first year. UW reported a 339 percent increase in ILL use by undergraduates, suggesting that, with WorldCat Local implementation, users who did not previously know about ILL were introduced to it as an available service. Deardorff notes that WorldCat Local shifts interlibrary loan from a "boutique" service into one that can expose "an immense universe of content that was previously hidden." ${ }^{4}$

The ease with which a user can place an interlibrary loan request from within WorldCat Local search results has resulted in an understandable increase in ILL borrowing requests at the University of Delaware Library as well. Prior to this implementation, users needed to seek out WorldCat via FirstSearch in the library's list of databases to search beyond the library collection using the WorldCat catalog. The library homepage featured a link for searching DELCAT and a link to lists of subscription databases, but it did not place emphasis on expanding a search to WorldCat. Now WorldCat Local is featured prominently on the library homepage, which encourages users to search for items held both by the University of Delaware Library and by libraries around the world.

\section{Interlibrary Loan Requests for Locally Available Materials: Literature Review}

Several research studies have explored the reasons that users place ILL requests for items that are already owned in the local collection. Existing studies, summarized below, have analyzed ILL request cancellation data and offered conclusions about the implications for library instruction, users' desire for expanded delivery services at their home libraries, the need for ILL policies to be made clear to users, and catalog and interface design. WorldCat Local introduces major changes to many facets of these types of library services and resources, so it is very relevant to examine ILL cancellations in the context of this relatively new discovery tool. Studies below discuss percentages of cancellations due to local availability; 
other common reasons an ILL request might be canceled include the requested item's age (recently published and older books are both difficult to borrow), format (many libraries will not lend audiovisual materials, for example), rarity, or cost.

Yontz et al. (2000) examined ILL cancellations at the University of Florida (UF) in 1998. They found that 17 percent of ILL requests in the first quarter of 1998 were canceled; 39 percent of these for the reason that the University of Florida owned the item. Their data indicated that 11 percent of those requests were placed by users who acknowledged that UF owned the title but wanted to request it in a different format without waiting for a checked-out copy to be returned, hoping (for instance) that a print item would be scanned for them. Yontz found that a much greater number of these requests were for articles rather than loans: 196 articles compared to 104 loans. The study concludes that better communication to users about policies, search techniques, and locations of materials need to come from public services staff to guide users to the materials they need. Yontz also discusses the role of "instant gratification" with requests for locally available items, which refers to those users who prefer placing an ILL request to searching the stacks for a print copy of an item. ${ }^{5}$

O'Brien's study (2004) of canceled ILL requests for materials held at the University of Illinois at Chicago Library of the Health Sciences was inspired by the Yontz article. He collected data on ILL cancellations during the 2002-2003 fiscal year and closely analyzed data from the 4 th quarter of that time period. The cancellation rate for FY2002-2003 was 18 percent, and the cancellation rate for the 4 th quarter was 21 percent. The O'Brien study found that 67 percent of the $4^{\text {th }}$ quarter cancellations were due to local ownership in either print or electronic format; the largest number of cancellations came from requests for journals that the library owned in print. O'Brien suggests that users who do not find an article on- line in full text immediately place an ILL request without checking to see if a print volume is available. He concludes that focused bibliographic instruction might help patrons locate and use material that is locally available to them. ${ }^{6}$

Page and Kuehn (2009) evaluated patterns of cancellation at Ohio State University (OSU) during 2007. They found that 20.5 percent of ILL requests were canceled in 2007, and 32 percent of those were canceled because the items were locally owned or available through OhioLINK, a consortium of which OSU is a member. The OSU researchers took a sample of the canceled requests and attempted to replicate the users' searches for the citations to understand why they may have submitted an ILL request for something already available at OSU. Data on the number of clicks from citation discovery to a full-text article were analyzed, but the study found no solid data to demonstrate that users placed an ILL request simply because it was easier than clicking through to find print holdings or full text. Page and Kuehn's study found that user status was not significant in their results, even though they expected that certain user groups might place a higher percentage of requests for locally available items. This study also found that more article than loan requests were canceled due to local access. ${ }^{7}$ Ohio State University was an early adopter of WorldCat Local and also has reported on ILL activity postimplementation, but Page and Kuehn's study was conducted prior to its launch at OSU. ${ }^{8}$

Murphey and Greenwood (2009) studied ILL request cancellations at the University of Mississippi from 2001 through 2007, hoping to determine which user groups might benefit the most from targeted instruction about ILL. They found that 23 percent of all ILL requests placed between 2001 and 2007 were canceled, with 48 percent of these cancellations because of local availability. Like previous researchers, Murphey and Greenwood found that more requests for articles than 
loans are canceled for this reason. Their analysis also concluded that, although the highest rate of cancellations is from undergraduates, graduate students also require assistance in locating locally available materials. This article also discusses the idea that increases in electronic subscriptions lead to more users believing all available items must be online, another contributing factor to the reasons users might be placing requests for items held in print. ${ }^{9}$

Most recently, a study (2010) of ILL request cancellations at Florida Gulf Coast University during fiscal year 2008-2009 found that 18 percent of ILL borrowing requests were canceled; of those, 32 percent of the cancellations were made because the requested material was locally available. The most common format for these canceled requests was print, and Reycraft notes that the ubiquity of digital formats and the increase of library users considered "digital natives" contributes to a lack of awareness of bound journals and microforms. She also comments on the inconvenience of obtaining a copy from a bound journal compared to scanning and digital delivery of ILL requests. One of Reycraft's recommendations for reducing ILL requests for locally held items is making changes to the library catalog, such as making journal holdings more visible or carefully avoiding jargon to better direct users to what they need. She concludes that the high number of requests for locally owned items in print indicates that there would likely be strong interest in a document delivery service within the library to scan articles in print for local users. ${ }^{10}$

\section{Methods}

This study examined ILL cancellation rates before and after the implementation of WorldCat Local at the University of Delaware Library. Data were collected and reviewed to see if the change in search interface and the flexibility of WCL affected users' success at identifying library materials available in the University of
Delaware Library. Using existing statistical reports, the total number of ILL requests, total number of canceled requests, and total number of canceled requests due to local availability were analyzed for academic years 2006-2007, 2007-2008, 2008-2009, and 2009-2010. Here, the academic year is defined as September 1 through May 31. These statistics differ from previously published University of Delaware ILL statistics reported to the Association for Research Libraries (ARL), as those statistical reports cover fiscal year activity.

WorldCat Local was implemented at the University of Delaware Library at the beginning of academic year 2008-2009. The implementation of WorldCat Local at UD coincided with the implementation of ILLiad for ILL request management; as a result, more detailed data and statistics are available for the latter two years of ILL activity. For example, comprehensive statistics broken down by request type (loan vs. copy) are not available for 2006-2007 or 2007-2008, but were compiled and considered for 2008-2010. Detailed data beyond the total numbers of ILL requests received and canceled based on library statistical reports were obtained using a custom SQL query on the library's ILLiad database.

\section{Results}

Data from four academic years of ILL activity showed that the number of total ILL request cancellations after implementation of WorldCat Local did not decrease, but the number of cancellations due to local holdings did decrease. In 2006-2007 and 2007-2008 respectively, prior to WorldCat Local at the library, 23.05 percent and 23.52 percent of all ILL requests were canceled. Of those, 72.76 percent and 73.17 percent were canceled because the requested item was locally available. These percentages are much higher than those calculated in other libraries' studies of this topic, suggesting that University of Delaware Library users were having trouble identifying local holdings and 
knowing when to place an ILL request for needed materials. In short, a significant number of ILL requests were submitted unnecessarily, either because the requesting researcher did not know the item was available locally, did not know how to obtain an item that was locally available, or was unfamiliar with ILL policies and hoped to obtain material in a format different from the library's copy.

Not surprisingly, the implementation of WorldCat Local resulted in a rising number of requests processed by ILL staff; some months show a 50 percent increase in activity from the previous year. The overall rate of ILL request cancellation also increased in the first year of WorldCat Local to 30.33 percent, though it did decrease in 2009-2010 to 22.34 percent. This second percentage is similar to cancellation rates prior to WorldCat Local implementation. The percentage of cancellations due to locally held items, though, declined significantly in the two years following the implementation of WorldCat Local. Out of the total number of canceled requests, only 43.77 percent in 2008-2009 and 54.77 percent in 2009-2010 of these were canceled because the requested material was available at the library. When these rates are compared to the previous years' figure of a 70 percent cancellation rate due to local ownership, a clear trend in ILL request cancellation and WorldCat Local appears.

Statistics on all ILL requests were placed through WorldCat Local during this time period were analyzed more closely for cancellation patterns. In 2008-2009, 21.70 percent of ILL borrowing requests received were submitted by users via WorldCat Local. A total of 25.72 percent of these requests were canceled, but only 25.46 percent of these cancellations were due to local availability. The overall number of requests canceled for this reason amounted to only 6.55 percent of all ILL requests placed through WorldCat Local. This percentage represents a significant decrease compared with previous years and overall ILL activity. In other words, requests placed by users searching WorldCat Local are much less likely to be cancelled because the requested item is available at the University of Delaware Library.

Similar patterns are evident in the 2009-2010 academic year. Users submitted 27.37 percent of all ILL requests via WorldCat Local, an increase from the previous academic year that indicates users are comfortable with the search tool and its requesting capabilities. A total of 25.78 percent of the requests placed through WorldCat Local were canceled, and only 17.91 percent of these were cancelled due to local availability. Overall, only 4.62 percent of ILL requests submitted via WorldCat Local were canceled because of local holdings. These percentages are evidence of WorldCat Local's effectiveness in reducing ILL requests that will be canceled and filled locally. These two years of data show a sharp decline in the number of ILL requests cancelled for local availability, and data on requests originating in WorldCat Local indicate that the drop in cancellations can be attributed to this new search interface. These data demonstrate that WCL is an effective tool for expediting users' research; this search and delivery interface might reduce confusion and more efficiently point researchers to those resources that are available at their university library.

Analysis of cancellation rates by request type showed that a greater number of photocopy requests were canceled due to local access than loan requests were, regardless of the request source. The majority of requests received via WorldCat Local are for loans of returnable items. However, data from requests placed using WorldCat Local show that cancellations for locally held materials are much more prevalent when the request is for a copy. In 2008-2009, 11.01 percent of the WorldCat Local requests for article copies were for locally available materials, but only 5.70 percent were for loans of books or other materials already owned by the library. In comparison, 17.33 percent of 


\begin{tabular}{|c|c|c|c|}
\hline Local ILI & $\begin{array}{l}\text { FIGUF } \\
\text { cellations be } \\
\text { Academic Y }\end{array}$ & $\begin{array}{l}\text { E } 1 \\
\text { fore and } \\
\text { ears } 200\end{array}$ & $\begin{array}{l}\text { WorldCat } \\
10\end{array}$ \\
\hline - Total ILL Bo & Requests Received & - Cancellec & ocal Holdings \\
\hline & & 2,960 & 2,798 \\
\hline 3,345 & 3,559 & & \\
\hline 19,946 & 20,684 & 22,301 & 22,873 \\
\hline 2006-2007 & $2007-2008$ & $2008-2009$ & 2009-2010 \\
\hline
\end{tabular}

customization of WorldCat Local according to local requesting policies is one of the service's greatest advantages, from a resource sharing perspective. In presenting the ILL request button on certain records only when an ILL request would be permitted according to local policies, users are better guided to use the call number information presented to them through WorldCat Local. Users also may learn when ILL requests

all ILL copy requests processed during that academic year were canceled due to local availability, while only 6.92 percent of loan requests were canceled for this reason. Data for the 2009-2010 academic year show similar cancellation rates and patterns. These numbers emphasize that serials holdings continue to present difficulties, both with users who have trouble interpreting holdings and users who may be hoping to receive all their articles electronically.

\section{Discussion}

With ILL requests used as a frame of reference, WorldCat Local is improving users' ability to locate and access materials available from the University of Delaware Library, either in print or electronically.

The fact that ILL requests increased, yet percentage of local cancellations decreased, after the launch of WorldCat Local indicates that it is an effective search tool both for locating citations and for obtaining materials once those citations are found. This move toward integration of multiple discovery tools and delivery interfaces helps users get what they need in as few clicks as possible. The are the appropriate step toward obtaining the resources discovered in the course of their research. The inability to place requests for available items reduces the time it might take a researcher to obtain needed materials: Users are not submitting an ILL request only to have ILL staff cancel it and refer them to a copy in the local stacks. For nonserial requests, WorldCat Local marks a significant improvement in helping users discover materials in their local libraries and reducing the time ILL staff spend looking up call numbers and canceling requests. This reduction in unnecessary requests redirects staff time to dealing with the increase in ILL borrowing requests and with processing incoming materials that have been sent from other libraries for a user.

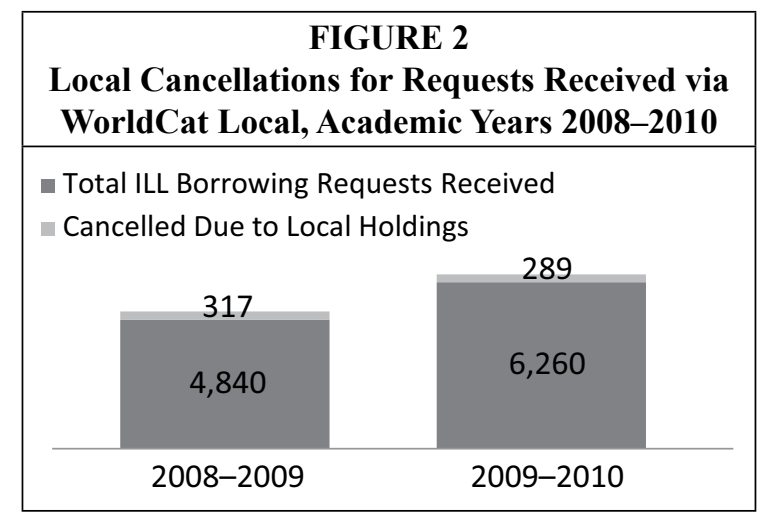




\begin{tabular}{|l|c|c|c|c|}
\hline \multicolumn{5}{|c|}{ TABLE 1 } \\
\hline & $\begin{array}{c}\text { Academic Year } \\
\mathbf{2 0 0 6 - 2 0 0 7}\end{array}$ & $\begin{array}{c}\text { Academic Year } \\
\mathbf{2 0 0 7 - 2 0 0 8}\end{array}$ & $\begin{array}{c}\text { Academic Year } \\
\mathbf{2 0 0 8}-\mathbf{2 0 0 9}\end{array}$ & $\begin{array}{c}\text { Academic Year } \\
\mathbf{2 0 0 9 - 2 0 1 0}\end{array}$ \\
\hline $\begin{array}{l}\text { Total ILL Borrowing } \\
\text { Requests Received }\end{array}$ & 19,946 & 20,684 & 22,301 & 22,873 \\
\hline Total Canceled & 4,597 & 4,864 & 6,763 & 5,109 \\
\hline $\begin{array}{l}\text { \% of Requests } \\
\text { Canceled }\end{array}$ & $23.05 \%$ & $23.52 \%$ & $30.33 \%$ & $22.34 \%$ \\
\hline $\begin{array}{l}\text { Canceled due to Local } \\
\text { Holdings }\end{array}$ & 3,345 & 3,559 & 2,960 & 2,798 \\
\hline $\begin{array}{l}\text { \% of Cancellations } \\
\text { due to Local Holdings }\end{array}$ & $72.76 \%$ & $73.17 \%$ & $43.77 \%$ & $54.77 \%$ \\
\hline
\end{tabular}

\section{TABLE 2}

University of Delaware Library ILL Borrowing Requests Received via WorldCat Local

\begin{tabular}{|l|c|c|}
\hline & $\begin{array}{c}\text { Academic Year } \\
\mathbf{2 0 0 8}-\mathbf{2 0 0 9}\end{array}$ & $\begin{array}{c}\text { Academic Year } \\
\mathbf{2 0 0 9}-\mathbf{2 0 1 0}\end{array}$ \\
\hline Total ILL Borrowing Requests Received & 4,840 & 6,260 \\
\hline Total Canceled & 1,245 & 1,614 \\
\hline \% Requests Canceled & $25.72 \%$ & $25.78 \%$ \\
\hline Canceled due to Local Holdings & 317 & 289 \\
\hline \% Cancellations due to Local Holdings & $25.46 \%$ & $17.91 \%$ \\
\hline
\end{tabular}

\section{TABLE 3}

Copy and Loans Total

\begin{tabular}{|l|c|c|}
\hline & $\begin{array}{c}\text { Academic Year } \\
\mathbf{2 0 0 8}-\mathbf{- 2 0 0 9}\end{array}$ & $\begin{array}{c}\text { Academic Year } \\
\mathbf{2 0 0 9}-\mathbf{2 0 1 0}\end{array}$ \\
\hline Total Copy Requests Received & 13,612 & 13,751 \\
\hline Copies Canceled due to Local Holdings & 2,359 & 2,190 \\
\hline Total Loan Requests Received & 8,689 & 9,122 \\
\hline Loans Canceled due to Local Holdings & 601 & 608 \\
\hline
\end{tabular}

\section{TABLE 4}

Copy and Loan Requests Received Via WorldCat Local

\begin{tabular}{|l|c|c|}
\hline & $\begin{array}{c}\text { Academic Year } \\
\mathbf{2 0 0 8}-\mathbf{2 0 0 9}\end{array}$ & $\begin{array}{c}\text { Academic Year } \\
\mathbf{2 0 0 9 - 2 0 1 0}\end{array}$ \\
\hline Copy Requests Received & 772 & 803 \\
\hline Copies Canceled due to Local Holdings & 85 & 109 \\
\hline Loan Requests Received & 4,068 & 5,457 \\
\hline Loans Canceled due to Local Holdings & 232 & 180 \\
\hline
\end{tabular}


Serial publications remain complex and problematic for researchers, just as previous studies have suggested. ILL staff at the University of Delaware routinely answer questions by e-mail, telephone, or in person from users who need assistance interpreting catalog holdings, whether they are viewing them in WorldCat Local or in DELCAT, to understand why their ILL request for something locally available was canceled. The need for wellmarked, user-friendly search interfaces with wording that avoids library jargon remains apparent. When users are presented with the Get It! button on a serial or article record in WorldCat Local, they may automatically submit an ILL request once they find that the article is not available electronically, as other studies have postulated. Users may submit the request despite print availability because they hope ILL staff will scan the document for them. They may also follow the Get It! link out of WorldCat Local into DELCAT, have trouble interpreting the holdings screen, and go back to submit an ILL request because they assume the library does not have what they need.

Requests for locally available electronic journals also are canceled by ILL staff, though not with the same frequency that requests for print serials are canceled. It is possible that users have trouble navigating interfaces of different electronic journal platforms and "give up" when they do not find what they need, as other studies have suggested. Electronic holdings may cause additional difficulty if users are expecting a direct link to a PDF and instead are being directed to the journal's Web page. These requests can be addressed both with changes to search interfaces and with additional instruction at public service points. Clearly defined policies at the point of need might also be helpful so that users might have a better sense of what may and may not be requested on ILL. In the case of article requests, if the appearance of request buttons were customized at the holdings level based on the journal volumes to which the library has access, even further progress could be made in reducing ILL requests for locally owned items.

Finally, cases in which there are multiple WorldCat bibliographic records for one item account for some cancellations of locally owned materials. Users may be sure that the library does not have an item based on the WorldCat Local record they are viewing, place an ILL request, and later find that the library does own the item. This problem likely comes from the "other editions and formats" screen in WorldCat Local, which does not always list locally available editions first. If the requested item is cataloged on a different bibliographic record from the one first selected by the user, local holdings will not be evident. Additionally, ongoing work to merge bibliographic records for the same item in WorldCat may help to alleviate some of these problems.

It is also notable that the overall ILL cancellation rate did not dramatically change after WorldCat Local implementation, yet the percentage of requests canceled due to local availability did decrease. Therefore, ILL staff were canceling more requests for reasons other than local holdings. Several factors contribute to the ILL Office's inability to obtain everything requested on ILL. WorldCat Local encourages users to find materials and request them on ILL, but some of these items may be rare, archival, or only available outside of the United States. While these requests demonstrate the effectiveness of WorldCat Local in helping users to identify relevant resources, not all of these items may be borrowed on interlibrary loan. The University of Delaware also saw a significant increase in the number of requests for audiovisual items after implementation, and not all libraries' policies allow them to provide CDs or DVDs on ILL; additionally, more recently released and popular material can be difficult to borrow because it is already in use at potential lending libraries. WorldCat Local also includes prepublication records, and users often click the 
ILL request button to try to obtain those books since the record does not clearly indicate the book is not yet available and will be published at a later date. At the University of Delaware, these requests are canceled and the user is asked to resubmit the request after the book's publication date, which is included in the cancellation message when available. ILL staff make every effort to locate a supplier for users' requests, but there are several factors that make some items impossible to deliver.

Though data from the University of Delaware Library's two years before and after WorldCat Local make strong suggestions about the utility of this new tool, further studies on the relationship between ILL and WorldCat Local use would be beneficial. Interviews or usability testing with students and faculty would provide great insight into researchers' use of this tool as well as to confirm or disprove theories about user behavior, ILL, and WorldCat Local. Previous research on ILL request cancellations for locally available materials have surveyed users to learn more about the reasoning behind their request. Interviews with ILL users would be a very beneficial next step in making connections between local resource identification and WorldCat Local.

\section{Conclusion}

This study confirms that, although WorldCat Local highlights ILL as a service and can drive a substantial increase in requests, it also works to solve a routine problem encountered by ILL staff and users: WCL helps to prevent ILL requests for materials that are locally available and will not be requested from another library, thus saving ILL staff time and guiding users to needed material more quickly than they may have found it with previous research tools. Data from the University of Delaware Library suggest that WorldCat Local may help users to better understand what is locally available to them in addition to those millions of items that can be requested from another library. Further research would be helpful in closely examining data on cancellations to look for patterns in requests that are placed for locally available materials. It is clear, however, that WorldCat Local makes great strides in saving both user and staff time in the context of local holdings and in controlling when a user is able to submit an ILL request during a catalog search.

\section{Notes}

1. Available online at www.udel.edu/aboutus/ [accessed 1 October 2010].

2. Available online at www.udel.edu/IR/fnf/index.html [accessed 1 October 2010].

3. Available online at www.oclc.org/services/brochures/212611usb_worldcat_local.pdf [accessed 1 Oct 2010].

4. Thomas Deardorff and Heidi Nance, "WorldCat Local Implementation: The Impact on Interlibrary Loan," Interlending and Document Supply 37, no. 4 (2009): 177-80.

5. Elaine Yontz, Priscilla Williams, and Jane Anne Carey, "Interlibrary Loan Requests for Locally Held Items: Why Aren't They Using What We've Got?" Journal of Interlibrary Loan,Document Delivery E Information Supply 11, no. 1 (2000): 119-28.

6. Kevin O'Brien, "Canceled Requests: A Study of Interlibrary Loan Requests for Items Held in a Medical Library Collection," Medical Reference Services Quarterly 23, no. 3 (2004): 17-23.

7. Jessica R. Page and Jennifer Kuehn, "Interlibrary Service Requests for Locally and Electronically Available Items: Patterns of Use, Users, and Canceled Requests," portal: Libraries and the Academy 9, no. 4 (2009): 475-89.

8. Deardorff and Nance, "WorldCat Local Implementation," 179-80.

9. Rebecca M. Murphey and Judy T. Greenwood, "Feasibility of Analyzing Interlibrary Loan Requests to Determine Instruction Needs," Journal of Access Services 6 (2009): 359-87.

10. Kimberly Reycraft, "Interlibrary Loan Requests Canceled Due to Availability: Problem or Opportunity?" Journal of Interlibrary Loan, Document Delivery, and Electronic Reserve 20 (2010): $33-42$. 